CHRISTINE MENNESSON*

University of Toulouse, France

\section{LUCIE FORTÉ}

University of Toulouse, France

\title{
GENDER CONSTRUCTION IN SPORTS, FAMILY HABITUS AND “GENDER REGIME”
}

\begin{abstract}
This article is based on data collected during a qualitative research on children's leisure practices and family socialization patterns. The paper focuses more specifically on the cross effects of gender and social class on the construction of body hexis and relationship to sports. The results show that several dimensions of family habitus must be taken into account: lifestyles, way in which parents divide the tasks of raising children and the relationship they have with social competition or gender norms. Moreover, taking these different dimensions into account must be accompanied by an analysis of the concrete modes of socialization within the family and the practice context.
\end{abstract}

Keywords: socialization; body hexis; relationship to sport; gender; social class.

\footnotetext{
\# Corresponding author: Université de Toulouse, F2SMH, pôle sport, Université Paul Sabatier, 118 route de Narbon-
} ne, 31062 Toulouse cedex 4, France.E-mail: christine.mennesson@univ-tlse3.fr 


\section{Introduction}

Childhood studies focus on the autonomy of children's cultures. They rarely analyze the effects of social class. Furthermore, research on social differentiation of sports practices generally does not focus on children's activities (Messner and Musto 2014). Studies on this topic have shown that the family's socioeconomic status has an impact on children's participation in sports (White and McTeer 2012). Several researchers analyzed this process from a qualitative perspective by focusing on the role of family socialization. The family culture appears to act as a key element in the construction of children's tastes in sports (Wheeler 2012; Dagkas and Quarmby 2012). In particular, the place occupied by sports in the family's lifestyle plays an important role (MacDonald et al. 2004; Mennesson, Bertrand \& Court 2016). Some authors have identified a family habitus (Tomanovic 2004; Lareau 2003) which acts as the organizing principle of the children's relationship to leisure activities and sports.

In this line, Bourdieu's theoretical framework offers some advantages for studying sports experiences among children. Indeed, Bourdieu (1980) insisted on the bodily dimension of habitus, which he defined as a set of dispositions which are acquired under specific conditions of existence and orient an individual's practices and representations. Therefore, the relationship a person has with sports constitutes one of the dimensions of his/her habitus. This framework also allows grasping the child-rearing practices of families in accordance with their lifestyle and their position in social space (Bourdieu 1979). Social position is based on the size and structure of the family's economic capital and cultural capital (Bourdieu 1979). It translates into a lifestyle, which encompasses a consistent set of family practices.

We know that boys and girls have different relationships to their bodies and to sports. Athletic involvement is more valued for boys than for girls, and it also provides boys with a privileged status in their peer group (Shakib, Veliz, Dunbar, \& Sabo 2011). Furthermore, involvement in a sport that is atypical for one's gender is judged less negatively for girls than for boys (Messner 2011). That being said, whereas the same family habitus may be appropriated differently (or not) by girls and boys and may promote differenciated (or not) practices, studies analyzing family habitus have paid little attention to children's gender-group membership and to the family's habitus appropriation. In this paper, we will consider that the product of family socialization notably depends on the gender division of child-rearing tasks and on what Pierre Bourdieu (1993) calls "the economy of affective relationships." Thus, in order to extend and complement Bourdieu's work, we will study the relationship between gender and social classes. Although some authors have included gender as a part of the cultural capital (Laberge 1995; Lovell 2000; McCall 1992; Skeggs 1997), or have considered it as a form of symbolic capital (Thorpe 2009), or have conceived it as a capital per se (Huppatz 2009), the habitus and field theory (Bourdieu 1979) did not include gender as a process which structures social space and social contexts (such 
as familial contexts). In this article, we will try to show that we can identify a family habitus and take into account its gendered dimensions in order to fully grasp the cross effects of gender and social class.

But, if it is possible to integrate the gender issue in the analysis of the family habitus, we will consider that the construction of gender cannot be studied independently of the context in which it takes place. In this regard, Connell's (2002) concept of gender regime provides useful tools for the study of gender construction, in particular athletic contexts. Moreover, Connell described what she called a "gender regime", which corresponds to a state of gendered social relations in a given institution or context. She identified four main components of the gender regime: (1) symbols (models of representation such as media images) (2) power relations (implicit and explicit physical and economic forms of pressure and consent) (3) gendered division of work (modes of differentiation connected to the work) (4) concrete modes of interindividual interaction. We will see that the analysis of children's leisure contexts as "gender regimes" enables us to highlight the state of gender social relations in these four components. Furthermore, we will argue that gender regimes (which are historically constructed) frame the gendered behaviours adopted by boys and girls. Indeed, we will show that the gender dimension of the habitus (Krais 2006; McCall 1992) can be used to analyze boys' and girls' individual behaviour in a given gender regime (e.g., in the context of a specific sport - Mennesson 2012).

\section{Methodology}

In this article, we mobilize data from research funded by the French National Research Agency on the children's bodily and sporting socialization. They have been collected during two studies dealing with sporting socialization of boys and girls between the ages of ten and eleven.

The first investigation was based on interviews with thirty French families followed for two years. Children were interviewed separately from their parents, so that they could express themselves more freely. During the interviews, we used ethnographic forms in order to encourage in-depth and repeated exchanges with respondents (Beaud 1996). The interviews were conducted during the last year of primary school and repeated during the first year of secondary school. The interview-guide used with children focused on their leisure activities and their parents' role. Two interview-guide were used with parents. The first, concerned their background and experience with leisure activities; the second pertained to the children and family's leisure activities as well as parent's educational practices. In order to facilitate the search for families in which the parents' social positions and their child's relationship to sports met our investigation criteria, the majority of participants were recruited through acquaintances. To compensate for the underrepresentation of participants from disadvantaged backgrounds, we extended our spectrum of investigation by soliciting two schools whose population mainly comes from lower-middle and lower classes. In the end, the 
interviews were conducted among eight lower class families, twelve middle class families, and twelve upper class families.

Table 1. Activities - social context - gender composition.

\begin{tabular}{|c|c|c|}
\hline Activities & Social context & $\begin{array}{c}\text { Gender } \\
\text { composition }\end{array}$ \\
\hline Football & $\begin{array}{c}\text { Popular and middle classes, peri-urban environ- } \\
\text { ment }\end{array}$ & Only boys \\
\hline Hockey & Middle and upper classes, urban environment & Only boys \\
\hline Rugby & Popular and middle classes, rural environment & Only boys \\
\hline Horse riding & Popular and middle classes, rural environment & $\begin{array}{l}\text { Mixed with a predomi- } \\
\text { nance of girls }\end{array}$ \\
\hline Climbing & Middle and upper classes, urban environment & Mixed \\
\hline Dance & Middle and upper classes, urban environment & Only girls \\
\hline Judo & Middle classes, urban environment & $\begin{array}{l}\text { Mixed with a predomi- } \\
\text { nance of boys }\end{array}$ \\
\hline New circus & Middle and upper classes, urban environment & $\begin{array}{l}\text { Mixed with a predomi- } \\
\text { nance of girls }\end{array}$ \\
\hline Gymnastics & $\begin{array}{l}\text { Popular and middle classes, peri-urban environ- } \\
\text { ment }\end{array}$ & $\begin{array}{l}\text { Mixed with a predomi- } \\
\text { nance of girls }\end{array}$ \\
\hline $\begin{array}{l}\text { Rythmic } \\
\text { gymnastics }\end{array}$ & Middle and upper classes, urban environment & Only girls \\
\hline
\end{tabular}

Source: own elaboration.

The second investigation used an ethnographic approach to analyze the gender regime in children's sports contexts. We studied a dozen physical activities, more or less gendered and invested by children from different social backgrounds. Thus, we observed different types of contexts: some of them reproduced gender norms, others had ambivalent effects and a minority of them questioned gender norms. Each context was studied through an ethnographic study lasting several months. The data were supplemented by interviews with parents, coaches and children.

All the interviews were analysed with a thematic analysis, on the basis of close reading of the corpus by the authors. Three main themes emerged from this: (1) the respective places of sports and artistic activities in the child's participation in clubs and associations (2) parents' experiences in leisure activities and parental attitudes toward mainstream forms of culture (3) the educational strategies of parents.

In the first part of the paper, we will present three children's sports biographies of girls intensively involved in sports, and three children's sport biographies of boys who practice little or no sport. We have chosen to present atypical cases from a gender point of view because these examples bring to light specific socialization processes - which are more difficult to grasp in the case of more conforming gender socialization. Indeed, gender socialization is often imposed on actors with the force of the natural. Thus, atypical cases, which question this naturalization process, are particularly interesting. We have also chosen to 
present individuals from different social classes in order to analyze the effects of belonging to a social group on the process of gender construction. Then, we will focus on two sports contexts: one which can be considered as "traditional": rhythmic gymnastics; and one more "innovative": new circus. In our research, these two activities were participated in by individuals coming from the same social classes. Therefore, the comparison will only focus on gender differences. The choice of these two activities is based on their very different relationship to dominant gender norms, and on the relatively similar social characteristics of their performers. In this second part of the paper, we will analyse the gender regimes of these sports contexts and we will study the impact of family habitus on children's engagement patterns. To this end, we will focus on two children's sport biographies of girls practising rhythmic gymnastics.

\begin{tabular}{|c|c|c|c|}
\hline Surname & Sports activities & Father's occupation & $\begin{array}{c}\text { Mother's occupa- } \\
\text { tion }\end{array}$ \\
\hline Hugo & No sports activities & $\begin{array}{c}\text { Lecturer in literature (public } \\
\text { sector) }\end{array}$ & $\begin{array}{c}\text { Lecturer in art } \\
\text { history (public } \\
\text { sector) }\end{array}$ \\
\hline Chloe & $\begin{array}{c}\text { Gymnastics, three times a } \\
\text { week, with competition }\end{array}$ & Surgeon (private sector) & $\begin{array}{c}\text { Engineer (private } \\
\text { sector) }\end{array}$ \\
\hline Aurelia & $\begin{array}{c}\text { Karate, three times a week, } \\
\text { with competition }\end{array}$ & Employee (public sector) & $\begin{array}{c}\text { Secretary (private } \\
\text { sector) }\end{array}$ \\
\hline Arthur & $\begin{array}{c}\text { Swimming, weekly, with- } \\
\text { out competition }\end{array}$ & Electrician & $\begin{array}{c}\text { Secretary (public } \\
\text { sector) }\end{array}$ \\
\hline Marius and & $\begin{array}{c}\text { Marius: Rugby, twice a } \\
\text { week, with competition } \\
\text { Theo: No sports activities }\end{array}$ & Technician (private sector) & $\begin{array}{c}\text { Middle manager } \\
\text { (public sector) }\end{array}$ \\
\hline Juliette and \\
Leonie & $\begin{array}{c}\text { Juliette: No sports activ- } \\
\text { ities } \\
\text { Leonie: Judo, twice a } \\
\text { week, with competition }\end{array}$ & Technician (public sector) & $\begin{array}{c}\text { Primary school } \\
\text { teacher (public } \\
\text { sector) }\end{array}$ \\
\hline Léa & $\begin{array}{c}\text { Rhythmic gymnastics, } \\
\text { three times a week, with } \\
\text { competition }\end{array}$ & Engineer (private sector) & $\begin{array}{c}\text { Engineer (private } \\
\text { sector) }\end{array}$ \\
\hline Clara & $\begin{array}{c}\text { Rhythmic gymnastics, } \\
\text { three times a week, with } \\
\text { competition, then new } \\
\text { circus }\end{array}$ & Educator (public sector) & $\begin{array}{c}\text { Librarian (public } \\
\text { sector) }\end{array}$ \\
\hline
\end{tabular}

Source: own elaboration 


\section{Children's Participation in Sport, Family Habitus, and Gender Con- struction: Children's sport biographies of non-sporting Boys Versus Girls Intensively Involved in Sports Sports Participation, Gender Construction and Family Habitus in Affluent Households}

In this first part, we will present the case of Hugo, who does not belong to a sport's club and does not like "male" physical activities; and the case of Chloe, who practices gymnastics three times a week and participates in high-level competitions. Both of them come from well-to-do families. Hugo's parents are University Research Professors in Human Sciences (his father is a literature specialist and his mother is an art historian). Chloe's father is a surgeon and her mother is an engineer. Both families have significant financial resources. However, two points distinguish them and play an important role in their children's socialization.

The first difference is that Hugo's parents are not very athletic and prefer artistic pursuits. The family can be characterized by a "cultured" lifestyle: Hugo's parents have little appreciation for sports and are used to frequenting museums, theatres and concert halls with their children. Hugo plays the piano and his parents strongly support this activity. Conversely, Chloe's parents have a strong sporting background and a sport-oriented lifestyle. Although they belong to an affluent socioeconomic group, they have little interest in cultural practices. Thus, while these two families have significant economic capital, their cultural capital and their relations with sports are very different. The difference can be explained by the parents' family backgrounds: Chloe's parents grew up in sports-oriented families with substantial economic resources, whereas Hugo's parents come from families of intellectuals.

More broadly, the two families have different relationships to the social world. Chloe's parents believe that playing competitive sports is something positive, especially because it provides an interesting training ground for social competition:

"It develops the will to go forward (...) I must admit that it's a good thing in life to have that fighting spirit: it is what makes you progress and go as far as possible." (Chloe's mother)

Chloe's parents want their children to learn "to push their limits" and to internalize competitive dispositions. To this end, they enrolled their children in elitist private schools. Hugo's parents also care about their children's social and academic achievement. But they believe that social success depends on a complete education and not on the expression of an ability to surpass others. They are not very keen on competitive sports. As they are more critical of social competition, their children attend public schools.

"Hugo practiced judo for a year, but the coach was very competitive, he pushed them a lot, and I definitely don't like that. To do 
everything to win and to outperform others is not really a value that I defend." (Mother of Hugo)

Secondly, the gender division of child-rearing tasks is strong in Chloe's family and weak in Hugo's. Chloe's mother no longer works in order to take care of her children, whereas Hugo's parents take turns caring for them. More generally, Chloe's parents want their children to conform to gender norms. They have chosen gymnastics for their daughter because they consider that this activity permits "to develop a beautiful, slim and graceful body." Thus, participation in competitive gymnastics fits well with the value system promoted by this family. Here again, the situation is very different in Hugo's family. His parents value a certain degree of non-conformity with gender norms. As a result, his mother is amused by his lack of interest in sport, supports him in his little inclination and greatly appreciates his abilities in the field of music. This deviation from gender norms in families with a high cultural capital was already observed in previous studies (Mennesson and Juhle 2012; Mennesson, Bertrand \& Court 2017).

Thus, several dimensions of family habitus explain the relatively atypical relationships these children develop with sports: their lifestyle (more or less oriented towards sports or culture), their relationship to social competition, the gender division of child-rearing tasks at home and the parents' attitudes toward gender norms. These different but interrelated elements broaden the scope of the family habitus analysis.

\section{Sports Participation, Gender Building, and Family Habi- tus in Modest-Income Households}

In this second part, we will present the case of Aurelia, who goes to karate three times a week and participates in competitions and the case of Arthur, who goes swimming once a week but has little interest in this activity. Aurelia and Arthur belong to lower-middle-class families: both mothers are secretaries, Aurelia's father is an employee in a public organization, Arthur's father is an electrician. The parents of these two children do not have a strong sports background and their participation in physical and fitness activities is particularly moderate and irregular. In short, the sporting experience of Aurelia and Arthur's parents does not allow us to differentiate their families. That being said, they have adopted very different strategies regarding their children's sports participation.

Aurelia's parents, especially her father, attach a great deal of importance to their children's sporting activities: her father has strongly influenced her sporting trajectory; he was the one who chose the sport she practices (a martial art) and he strongly encouraged her to compete. He believes that she must learn to "fight for herself" in sports and in life. Having experienced an upward social mobility trajectory, he wishes for his children to do the same. To do so, he believes his daughter must learn to be independent: 
"Sports, fighting sports and competition are important because they teach you that you have nothing without work. Nothing is taken for granted in life. In the world we live in... no pain no gain.” (Aurelia’s Father)

Although, like Chloe's parents, he is favourable to athletic and social competition, he takes a different position regarding gender norms. Aurelia's parents equally share the child-rearing tasks, and they encourage their daughter not to conform to gender norms. Their desire to rise socially translates into gender-role mobility for girls:

"I don't like the caricature of the delicate girl, I don't want a "la-di-da" girl... Girls don't need too much protection, it's not good for them. I would like her to go as far as possible in her studies and to choose a job that she likes... But above all, I want her to work and not to depend on a man. So that if one day her boyfriend bothers her, she will be able to go away and to lead her own life." (Aurelia's Father)

Unlike Hugo's parents, Arthur's parents regret that their son is not more athletic. However, they do not offer a family socialization pattern that fosters the development of an inclination to participate in sports. Two points differentiate them from Aurelia's family: on the one hand, they do not have a strong desire to see their son rise socially. The father comes from a tradesman family, and he would like his son to choose a manual trade as well. On the other hand, their family structure is characterized by a relatively pronounced gender division: it is mainly Arthur's mother who is in charge of raising him. She isn't very athletic and she transmitted to him her interest in reading. She has adopted a "motherly" style of raising children which limited her son's relationships with his peers. As a result, Arthur has few opportunities to participate in sports activities. Thus, in Arthur's case, the lack of interest in sports is not the result of a parental child-rearing strategy, but the (unintended) consequence of the fact that he is an only child, essentially raised by his mother - moreover by a mother who is not particularly interested in sports:

"He's not very athletic, you always have to push him. We'd like him to be a little more voluntary for physical activities, but he doesn't like that. We forced him to practice swimming and he often asks if he can give up... It's complicated because my husband doesn't have much time to play sports with him. And when he has time, he prefers to teach him how to do odd jobs. Arthur enjoys doing manual activities with his father." (Arthur's Mother) 
These two examples confirm the influence of parents' relationship with athletics and gender norms in their children's sports participation. But they also highlight the complexity of these processes. Indeed, Aurelia's father's social trajectory is more decisive than his sporting experience to explain his very favourable attitude to competition. Moreover, Arthur's example shows that parenting practices sometimes produce unintended results.

\section{The role of affective relationships' economy}

Our last two cases will allow us to discuss the role of the family habitus in children's sports participation. Some of the families interviewed have same-sex siblings. In some cases, although they have been confronted with an apparently similar family habitus, children have quite different relationships with sports. A careful examination of these cases shows that the socialization patterns used for same-sex siblings are not always identical. This is the result of two processes. First of all, the family habitus is not necessarily homogeneous, since the two parents may adopt different positions. (Lahire 1998) Moreover, and in line with Pierre Bourdieu's proposals concerning the affective relationships' economy, the types of identification and relationships privileged within a family can modulate the effects of family habitus. Two families (the family of Marius and his brother Theo, and the family of Juliette and her sister Leonie) clearly illustrate these processes.

Both families belong to the middle-class and have similar economic resources. Both fathers have participated in competitive sports; both mothers are not very athletic and promote cultural and manual activities such as drawing. The family habitus is thus divided with regard to sport. In addition, Marius and Leonie (who respectively compete in rugby and judo) have a strong relationship with their father and are engaged in informal physical activities with him; Juliette and Theo do not play sports regularly and are less attracted to physical activities. They are described as being closer to their mothers, and, as their mothers, they love reading.

"They're both very different. Juliette is more quiet, more calm, I would say that she looks more like me; while Léonie is the sportswoman of the family, like her father." (Juliette and Leonie's mother)

"The older (Theo) is more interested in art, he doesn't like sport very much. Being quiet at home and playing guitar suits him perfectly. While the youngest (Marius) really needs to move, he loves sport, he loves competition...he really looks like my husband." (Marius and Theo's mother)

Thus, specific intra-family relationships are likely to modify the effects of family socialization (Mennesson, Bertrand et Court 2017). Indeed, when parents' points of view are different (like in these two families), the relationships that their children establish with sport can be very contrasted within the siblings. 


\section{Connecting Habitus and Gender regime to understand children's behaviors in sports and artistic contexts} "Rhythmic gymnastics" and "New Circus": two different gender regimes

These two activities reached gender and social differentiated audiences. Rhythmic gymnastics only includes girls (10) from the middle and upper classes, mainly from the economic fractions. Girls train three times a week and compete at a good level. The circus brings together girls and boys ( 7 girls and 5 boys), also from middle and upper classes, but more often from cultural fractions. Children train twice a week and give two shows a year.

In these two practice contexts, power relations between the sexes and gender division of labour are very different. Rhythmic gymnastics is supervised by two women who defend a quite traditional vision of femininity. In the circus association, a man and a woman voluntarily supervise the group and intervene with children in an undifferentiated way. The ethos and body hexis valued in these two activities are also very different. Rhythmic gymnastics is characterized by an ethic of effort, work and seriousness. The body is worked and shaped to meet the standards of the "ideal" female body, especially grace and slimness. "Being beautiful" is a permanent constraint which is repeated throughout the sessions. In new circus, self-expression is more important than asceticism. The body may deviate from gender norms if it is part of an artistic project. For example, we sometimes observed girls catching boys. In these two contexts, interactions between children and coaches and between children are different. In rhythmic gymnastics, the coaches are very directive and the children are reminded to discipline themselves as soon as they relax: "Stand up straight, watch your head, try again, be beautiful, more beautiful!" Girls compete for a place on the team and try to achieve gendered norms better than others. In circus, coaches have more equal relationships with children and they encourage them to challenge gender norms. Girls learn to take risks and boys to express their creativity. Girls and boys practice and talk easily with children of the opposite sex, unlike many mixed sports (Messner 2000; Musto 2014).

Thus, these two contexts reveal opposite gender regimes: while one reproduces gender norms, the other challenges them. As a result, the gender norms that children learn by body in the two activities are different. This example reveals the importance of artistic and sports activities in gender construction. They show that the latter can play a role in the construction of more or less gendered patterns of sociability and skills. Obviously, no activity is inherently innovative or traditional: it depends on the supervision and learning methods adopted by coaches and on institutionalised cultures. 


\section{Differentiated appropriations: the importance of habitus}

To illustrate the influence of family habitus on children's investment in sports contexts, we propose to focus on two girls practicing rhythmic gymnastics. The first, Lea, is very involved during training. The coaches identify her as the best gymnast in the group and define her as a "beautiful gymnast". Her parents are both engineers. The second, Clara, shows less enthusiasm. Coaches often blame her for not being graceful enough. Her mother is a librarian and her father is an educator. Two points distinguish Lea and Clara’s family socializations.

The first difference concerns the parental sporting experience and their appreciation of sport and competition. Both Lea's parents played competitive sports when they were young. They strongly value this modality of practice. Clara's mother has little experience in sports. Her father has a brief experience of competitive swimming. He has very bad memories of it. As a result, both of them are not very enthusiastic about intensive sport and competition.

The second difference concerns the distribution of child-rearing tasks according to gender. Lea's mother works part-time to care for her children and does most of the parenting on her own. Conversely, Clara's parents have an egalitarian view of their parental role. For example, when Clara's younger brother was born, both of them took a few months of parental leave. More generally, Lea's and Clara's parents value different (and even opposed) gender norms. Lea's mother appreciates the rigour of artistic gymnastics, but also its effects on her daughter's body. She believes that this practice permits Léa to have "a beautiful head posture", to "stand up straight" and to learn to "be graceful." According to her, thanks to gymnastics, her daughter is constructing a distinctive female body hexis. She thinks this body hexis will be an advantage on the labour market:

"- Thanks to rhythmic gymnastics, she stands up straight, she has a beatiful head posturę, she looks like a ballerine... Nowadays few children know how to behave correctly, they are all slumped... (Lea's mother)

- And that means a lot to you? (Investigator)

- Oh yes! Even later, when she will present herself for a job interview for example, if she does not know how to sit and stand, it is not even worth going there! It's important to make a good impression." (Lea’s Mother)

Conversely, Clara's parents do not like the gender models upheld by rhythmic gymnastics. Her father expresses it clearly:

"I don't like this, all those sequins, those forced smile, I have the impression of seeing barbies dolls." 
Although they don't like this activity, Clara's parents agreed to let her practice rhythmic gymnastics because she insisted: she wanted to follow one of her girlfriends. But Lea has difficulty complying with the gender regime which characterizes this activity. Unlike Lea, her parents never wanted her to pay attention to her appearance. They prefer that she feel "comfortable with her body" rather than look like "girls in magazines." It is fair to say that in Lea's case, the gendered disposition transmitted during her familial socialization favor the internalization of the rhythmic gymnastics' gender norms. Conversely, the gendered dispositions that Clara built during her family socialization complicate this process (Mennesson 2012).

\section{Conclusion}

The examples analyzed in this paper show that it is necessary to take into account family patterns of gender construction to understand children's sports practices. We suggest that the relationship to gender norms should be considered as one of the elements of the family habitus. In some more or less "egalitarian" families from the cultural fractions of the middle and upper classes, parents' preference for arts and applied arts is the same for all children and takes the same form regardless of their sex. In sports, these parents prefer less gendered activities or activities which challenge gender norms. In other families from the economic fraction of middle and upper classes characterized by a pronounced gender division, all children are encouraged to participate intensively in sports. However, girls are oriented toward "female" activities and boys toward "male" activities. These processes are complicated in some families where parental encouragements differ according to the sex of the parent. In such cases, the economy of affective relationships can promote relationships to sports that either deviate from gender norms or conform to them.

Finally, several dimensions of the family habitus explain children's relationship with sports: their lifestyle (more or less oriented toward sports or culture), their relationship to social competition, the gender division of child-rearing tasks and the parents' attitudes toward gender norms. These different but interdependent elements extend the scope of the family-habitus analysis. Moreover, it is relevant to combine this approach with an analysis of the concrete modes of socialization of the activities in which children are involved and in particular the gender regimes of sports activities. Indeed, the ways in which children appropriate these activities depends on the more or less positive relationship they have with their practices conditions; and more specifically on the more or less congruence between the dispositions constructed during their family socialization and those which are valued by the gender regime at work in the context of their practice. 


\section{REFERENCES}

Beaud, Stéphane. 1996. "L'usage de l'entretien en sciences sociales. Plaidoyer pour l'entretien ethnographique." [The use of interview in social sciences. Advocacy for ethnographic interview] Politix 9: 226-257.

Bourdieu, Pierre. 1993. "A propos de la famille comme catégorie réalisée." Actes de la Recherche en Sciences Sociales 1: 32-36.

Bourdieu, Pierre. 1984 [1979]. Distinction: A social critique of the judgement of taste. Cambridge: Cambridge University Press.

Bourdieu, Pierre. 1990 [1980a]. The logic of practice. Stanford: Stanford University Press.

Connell, Raewyn. 2002. Gender. Cambridge: Polity Press.

Dagkas, Symeon \& Thomas Quarmby. 2012. "Young peoples' embodiment of physical activity: The role of the "pedagogized" family." Sociology of Sport Journal 29(2): 210-226. DOI: 10.1123/ssj.29.2.210

Huppatz, Kate. 2009. "Reworking Bourdieu's "capital": Feminine and female capitals in the field of paid caring work.” Sociology 43(1): 45-66. DOI: 10.1177/0038038508099097

Krais, Beate. 2006. "Gender, sociological theory and Bourdieu’s sociology of practice." Theory, Culture \& Society 23(6): 119-134. DOI: 10.1177/0263276406069778

Laberge, Suzanne. 1995. "Toward an integration of gender into Bourdieu's concept of cultural capital." Sociology of Sport Journal 12: 131-146.

Lahire, Bernard. 1998. L'homme pluriel. Paris: Seuil.

Lareau, Annette. 2003. Unequal childhoods: Class, race, and family life. Berkeley, CA: University of California Press.

Lovell, Terry. 2000. "Thinking feminism with and against Bourdieu." Feminist Theory 1(1): 11-32. DOI: $10.1177 / 14647000022229047$

McCall, Leslie. 1992. "Does gender fit? Bourdieu, feminism and conceptions of social order." Theory and Society 21(6): 837-867. DOI: 10.1007/BF00992814

McNay, Lois. 1999. "Gender, habitus and the eld: Pierre Bourdieu and the limits of reflexivity." Theory, Culture \& Society 16(1): 95-117. DOI: 10.1177/02632769922050430

Macdonald, Doune, Sylvia Rodger, Jenny Ziviani, David Jenkins, Jenny Batch, \& Judy Jones. 2004. "Physical activity as a dimension of family life for lower primary school children." Sport, Education and Society 9(3): 307-325. DOI: 10.1080/13573320412331302412

Mennesson, Christine. 2012. "Gender regimes and habitus: An avenue for analyzing gender building in sports contexts." Sociology of Sport Journal 29(1): 4-21. DOI: 10.1123/ssj.29.1.4

Mennesson, Christine, Julien Bertrand \& Martine Court. 2016. "Forger sa volonté, s'exprimer: Les usages socialement différenciés des pratiques physiques et sportives enfantines dans les classes moyennes." [Forging one's will, expressing oneself: The socially differentiated uses of the physical and sporting practices of children in the middle classes] Sociologie 4(7): 393-438.

Mennesson Christine, Julien Bertrand \& Martine Court. 2017. "Boys who don't like sports: family lifestyle and transmission of dispositions." Sport, Education and Society https://doi.org/10.1080/13573 322.2017.1361397.

Mennesson, Christine \& Samuel Julhe. 2012. "L'art (tout) contre le sport. La socialisation culturelle des enfants des milieux favorisés." [Art (all) against sport? Cultural socialization of children from privileged backgrounds] Politix 99: 109-128. DOI: 10.3917/pox.099.0109

Messner, Michael. 2000. "Barbie girls vs. sea monsters: Children constructing gender." Gender and Society 14(6): 765-784. 
Messner, Michael. 2011. "Gender Ideologies, Youth Sports and the Production of Soft Essentialism." Sociology of Sport Journal 28: 151-170.

Messner, Michael \& Michela Musto. 2014. "Where are the kids?” Sociology of Sport Journal, 31: 102-122.

Musto, Michela. 2014. "Athletes in the Pool, Girls and Boys on Deck. The Contextual Construction of Gender in Coed Youth Swimming." Gender and Society 28(3): 359-380. DOI: $10.1177 / 0891243213515945$

Shakib, Sohaila, Philip Veliz, Michele Dunbar \& Don Sabo. 2011. "Athletics as a source for social status among youth: Examining variation by gender, race/ethnicity, and socioeconomic status." Sociology of Sport Journal 28(3): 303-328.

Skeggs, Beverley. 1997. Formations of class and gender. London: Sage.

Thorpe, Holly. 2009. "Bourdieu, feminism and female physical culture: gender reflexivity and the habitus-field complex." Sociology of Sport Journal 26(4): 491-516.

Tomanovic, Smiljka. 2004. "Family habitus as the cultural context for childhood." Childhood 11(3): 339360. DOI: $10.1177 / 0907568204044887$

Wheeler, Sharon. 2012. "The significance of family culture for sport participation." International Review for the Sociology of Sport 47: 235-252. DOI: 10.1177/1012690211403196

White, Philip \& William McTeer. 2012. "Socioeconomic status and sport participation at different developmental stages during childhood and youth: Multivariate analyses using Canadian national survey data." Sociology of Sport Journal 29(2): 186-209. DOI: 10.1123/ssj.29.2.186 